1. Department of Preventive Paediatrics,

Children Hospital and Institute of

Child Health, Multan.

2. Head of Paediatric Medicine, Children Hospital and Institute of Child Health, Multan.

3. Nutritionist,Department of preventive pediatrics, Children Hospital and Institute of Child Health, Multan

4.Social Welfare Officer, Children's Hospital \& the Institute of Child Health Multan

Correspondence Address: Dr. Saadia Khan Department of Preventive Paediatrics, Children Hospital and Institute of Child Health, Multan.

drkhanchc@gmail.com

Article received on:

22/07/2015

Accepted for publication: 00/00/2015

Received after proof reading: 00/00/0000

\title{
BREAST FEEDING;
}

AWARENESS AND COMPLEMENTARY FEEDING IN MOTHERS OF CHILDREN WITH SEVERE ACUTE MALNUTRITION AT NUTRITION STABILIZATION CENTRE CHILDREN HOSPITAL AND INSTITUTE OF CHILD HEALTH MULTAN.

\section{Dr. Saadia Khan', Professor Dr. Imran Iqbal' ${ }^{2}$ Reema Arshad ${ }^{3}$, Dr. Kamran Ishfaq ${ }^{4}$}

ABSTRACT: . . . Background: Breast feeding is the most natural way of feeding the infants and help to reduce child mortality and morbidity and millions of deaths could be prevented each year if mothers were aware of benefits of exclusive breast feeding for $4-6$ months and early initiation of breast feeding. Objective:To evaluate the awareness regarding breast feeding and complementary feeding in mothers of severely malnourished children. Study Design: This is a descriptive /cross sectional study. Place and duration of study: This study was conducted at the department of preventive pediatrics Children hospital and institute of child health, Multan from March 2013 to September 2013. Materials and Methods:This study included a total of 100 females that were the mothers of malnourished children visiting the follow up room of department of preventive pediatrics Children hospital and institute of child health, Multan. A questionnaire was designed and others were interviewed in detail after taking proper consent. Results:In this study, the mean age of the sample was25years +/_3 years. 70 $\%$ females (70/100) were from urban areas while $30 \%(30 / 100)$ were from rural areas. Of the 100 respondents 54\%(54/100) of mothers were illiterate and this study showed that $99 \%(99 / 100)$ considered breast milk safe and effective than other feeds but practically only $23 \%(23 / 100)$ babies were breast fed while $77 \%(77 / 100)$ were bottle fed. Pre-lacteal feed was given by $82 \%(82 / 100)$. According to $58 \%$ (58/100) mothers there should be a early initiation of breast feeding, while $57 \%(57 / 100)$ were un aware of the facts that clostrum should be given while 43 $\%(43 / 100)$ of then considered it unhealthy and non effective,82\%(82/100) considered 4 months a period of exclusive breast feeding,61\% (61/100) were counseled by doctors regarding the benefits of breast feeding, $50 \%(50 / 100)$ were aware of the use of exclusive breast feeding as a contraceptive tool and $34 \%(34 / 100)$ were aware of its importance for the prevention of breast cancer. Conclusion:The findings of the study indicated the various important policy implications for the intervention of breastfeedig. Strategies to encourage mothers to follow breastfeeding recommendations should concentrate on improving their knowledge.

Key words: $\quad$ Awareness, breastfeeding, mothers, child malnutrition, stabilization:

Article Citation: Khan S, Iqbal I, Arshad R, Ishfaq K. Breast feeding; awareness and complementary feeding in mothers of children with severe acute malnutrition at nutrition stabilization centre children hospital and institute of child health multan. Professional Med J 2015;22(12):1531-1534. DOI: 10.17957/ TPMJ/15.3030

\section{INTRODUCTION}

Malnutrition is a common health problem of Pakistan and according to National nutrition survey $2011,15 \%$ of the children are severely malnourished and poor feeding practices that lack of breast feeding and complementary feeding contributes a lot to malnutrition. ${ }^{1}$ Adequate nutrition is essential in early childhood to ensure healthy growth and development of child. ${ }^{2}$ Breast milk is elixir of life for babies and is available free of cost with no storage issues everywhere but now people are refusing to get its benefits. ${ }^{3}$ The reduction of infant and young child malnutrition is essential for the achievement of Millennium Development goals (MDGs)and for that importance of breastfeeding is accepted globally ,In 2001,World Health Organization declared that infant should be exclusively breast fed for six months and initiation of complementary feeding is necessary after six months along with breastfeeding. ${ }^{4}$ It is stated that millions of deaths could be prevented each year ifall babies should be breast feed for 4-6 months and there is early initiation of complementary feeding. ${ }^{5}$ 
Non breast fed babies have 11 times more chances of diarrhea and 15 times more chances of having pneumonia as compared to breastfed babies. In spite of too much benefit of breastfeeding mothers are now not well to nurture their babies with this precious gift of nature and prefer bottle feeding. According to Pakistan demographic and Health survey 2012-2013 just $37 \%$ of children under 6 months are breast fed and rate of early initiation of breastfeeding is just $28 \%$. Recently for the management of malnourished infants less than 6 months a project MAMI, Management of Acute Malnutrition is introduced with an objective to establish breast feeding in malnourished children along with early initiation of complementary feeding. ${ }^{6}$ If we have to improve health statistics we have to focus on primary health care and preventive pediatrics and there is a need to educate mothers. The rationale of carrying out this study was that to assess the knowledge of mothers regarding breastfeeding and complementary feeding and to counsel them for its importance and to tackle all their myths and beliefs regarding breastfeeding.

\section{MATERIALS AND METHODS}

This study was carried out at the department of preventive pediatrics Children hospital and institute of child health, Multan from March 2013 to September 2013. The study was descriptive /cross sectional. A questionnaire was designed and all mothers were interviewed in detail after taking proper consent. A questionnaire was discussed with two senior doctors (>8 years' experience) working at the preventive pediatric department, the chidlren's hospital \& the institute of child health Multan. It was revised to incorporate the recommended improvements. Data was analyzed statistically the means of portable IBM Statistics (Statistical Package for Social Sciences) version 20. The researcher used descriptive statistics, which include frequency, percentage, mean and standard deviations. Respondents' anonymity and confidentiality were ensured. Inform consent was obtained from all the respondents, they were answered calmly. This study included a total of 100 females that were the mothers of malnourished children visiting the follow up room of the department of preventive pediatrics Children hospital and institute of child health, Multan. Respondents voluntarily participated in this study. Respondents were encouraged and briefed to ask for the additional information or questions.

\begin{tabular}{|c|c|}
\hline Sample size & 100 females \\
\hline Mean age & 25years $+/$ 3 years \\
\hline Area & $\begin{array}{c}70 \% \text { females }(70 / 100) \text { were from urban } \\
\text { areas while } 30 \%(30 / 100) \text { were from rural } \\
\text { areas. }\end{array}$ \\
\hline Education & \begin{tabular}{c}
$46 \%$ of females were literate. \\
\hline \multicolumn{2}{|c|}{ Table-I. Demographic Characteristics of women } \\
$(\mathrm{n}=100)$.
\end{tabular} \\
\hline
\end{tabular}

\section{RESULTS}

In this study the mean age of sample was 25years +/3 years. $70 \%$ females (70/100) were from urban areas while $30 \%(30 / 100)$ were from rural areas. Of the 100 respondents $54 \%(54 / 100)$ of mothers were illiterate and this study showed that $99 \%$ (99/100) considered breast milk safe and effective than other feeds but practically only $23 \%(23 / 100)$ babies were breast fed while $77 \%$ (77/100) were bottle fed. Prelacteal feed was given by $82 \%(82 / 100)$. According to $58 \%$ $(58 / 100)$ mothers there should be a early initiation of breast feeding, while $57 \%(57 / 100)$ were un aware of the facts that clostrum should be given while $43 \%$ (43/100) of then considered it unhealthy and non effective, $82 \%(82 / 100)$ considered 4 months a period of exclusive breast feeding, $61 \%$ $(61 / 100)$ were counseled by doctors regarding the benefits of breast feeding, $50 \%$ (50/100) were aware of the use of exclusive breast feeding as a contraceptive tool and 34\% (34/100) were aware of its importance for the prevention of breast cancer. $93 \%(93 / 100)$ mothers were aware of benefits of complementary feeding but only 54\% (54/100) were giving it while $46 \%(46 / 100)$ considered it to cause pneumonia. $68 \%(68 / 100)$ of mothers were using cerelac as complementary feed.

Figure-I. described the distribution of respondents by their knowledge about the benefits of breast feeding. Of the 100 respondents 99 percent of the respondents agreed about the benefits of breast 
feeding and 1 percent of the respondent were not agreed.

\section{Benefits of breast feeding}

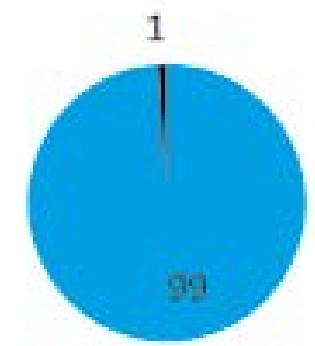

\section{= breast feeding best $\boldsymbol{m}$ breast milk not good}

Figure-1. Befenits of breast feeding

Figure 2 describes the distribution of respondents by their feeding pattern. Of the 100 respondents 77 percent respondents were using the bottle feeding and 23 percent respondents were agreed about breast feeding is very important for the batter health of child.

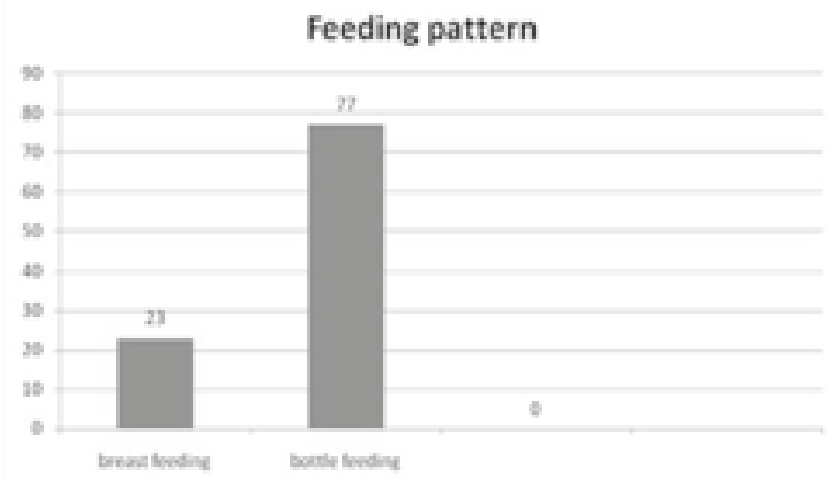

Distribution of respondents by their feeding pattern.

\section{DISCUSSION}

Breast feeding is the natural way of nurturing babies. This research was done with an objective to assess the awareness and knowledge of mothers of severely malnourished mothers regarding breast feeding and complementary feeding. Despite of various efforts and emphasis on breastfeeding worldwide unluckily breast feeding trend and rate of exclusive breast feeding are very low in Pakistan as compared to other Asian countries. ${ }^{7}$ This research shows that although $99 \%$ were aware that breast feeding is the best but practically just $23 \%$ of them breast fed their babies and $77 \%$ were giving bottle feeding. These results are similar to Pakistan Demographics and Health survey 2012-2013 that shows that Pakistan has lowest exclusively breast feeding rates in Asia 37\% and no competitor in the race of bottle feeding while prevalence of breast feeding in srilanka is $76 \%$, Nepal is $70 \%$,Bangladesh is $64 \%$,India $46 \%$.One study from Yemen also emphasis the role of exclusive breast feeding and early complementary feeding in reducing the children mortality. ${ }^{8}$ Similarly study done at Karachi reveals that $50 \%$ of sample population has no awareness regarding breastfeeding and importance of clostrum, In our study $43 \%$ considered it unhealthy. ${ }^{9}$ This shows that despite the well known benefits the increasing trends of bottle feeding and decreasing trends of breastfeeding are due to urbanization and advertisements of breast feeding substitutesand lack of proper implementation of National Breast feeding legislation. ${ }^{10}$ This study showed that complementary feeding practices are also not satisfactory and $46 \%$ of mothers not giving it to their babies with a fear of pneumonia, these results are similar with other studies and poor complementary feeding is a contributory factor increasing burden of malnutrition in age group between 6 months to 18 months..$^{11,12}$ This study suggest that there should be more focus on primary health care bygovernment and lady Health workers programmes need to be strengthen and policies should be planned for proper guidance of mothers and most important is there is proper check over breast Milk substitute sale and advertisement. This data reveal that Breast feeding trends seems to be vanishing and bottle feeding is a very common practice, and most of the mothers were giving commercially available cereals as initial complementary diets. Health education and awareness is the demand of the day.

Copyright (C) 02 Oct, 2015.

\section{REFERENCES}

1. Agha DA,MaqboolS,Anwar S.Is poverty or lack of nutrition awareness the main cause of malnutrition in children,PakPaed J2005;29:63-67. 
2. Harold Alderman and MeeraShekar. Nutrition, Food security and health. Nelson text of Pediatrics. 2011.p.171.

3. Mahmood S, Atif MF, MujeebSS. Assestment of nutritional beliefs and practices in practices in pregnant and lactating mothers in urban and rural areas of Pakistan. Jpak med Assoc.1997;47:60-62.

4. World Health Organization (WHO), 55th World Health Assembly. Infant and young child nutrition. World Health Organization, 2002 (WHA55.25).http://apps. who.int/gb/archive/pdf_files/WHA55/ewha5525.pdf.

5. World health organization. Nutrition: challenges, 2005.

6. Bhutta, ZA, Hafeez, A,RizviA,AliN,Khan Ahmed F. Reproductive,maternal, newborn and child health in Pakistan: Challenges and oppurtunities. Lancet 2013;381:2207-2218.

7. Akhter, Awareness of breast feeding in females of lower socio-economic group in Karachi; Medical channel 2009;15(4).19-20.

8. MoriskyDE, KarSB, ChaudaryAS, ChenKR, ShaheenM. Breast feeding practices in Pakistan, Journal of Nutrition .2002;1:137-142.
9. Shazia M, Salma S, Tesheem K, yasmeen M, Rubina. Assessment of infant feeding practices at tertiary care hospital. JPMA.dec.2010.

10. Srivastavan N, Sandhu A. Infant and child feeding index. Indian journal pediatrics 2006; 73:767-770.

11. BahlR, et al. Infants feeding patterns and risks of death and hospitalization in first half of infancy: multicentriccohotstudy. World health organization. vol.83.no.6.Geneva June 2005.

12. Levels and trends in child malnutrition, The United Nations Children's Fund, the World Health Organization and the World Bank 2012.p.4.

13. National nutritional survey 2011. Planning commission, planning and development division Government of Pakistan.

14. The millennium Development Goals Report 2013. Published in United Nation, New York.US13-26318June 2013.

15. Pakistan demographic and health survey (preliminary report). Federal Bereau of statistics, statistics division 2012-2013.

\section{AUTHORSHIP AND CONTRIBUTION DECLARATION}

\begin{tabular}{|c|c|c|c|}
\hline Sr. \# & Author-s Full Name & Contribution to the paper & Author $=\mathbf{s}$ Signature \\
\hline 1 & Dr. Sadia Khan & Main investigation, Design & \\
\hline 2 & Prof. Dr. Imran Iqbal & Find the erlevent literature & \\
\hline 3 & Reema Arshad & $\begin{array}{l}\text { and review. } \\
\text { Design the questionaire and }\end{array}$ & \\
\hline 4 & Dr. Kamran Ishfaq & $\begin{array}{l}\text { Set the formate and } \\
\text { reference citation. }\end{array}$ & \\
\hline
\end{tabular}

